\title{
Daptomycin Experience Between Years 2009-2013: Review of 139 Cases
}

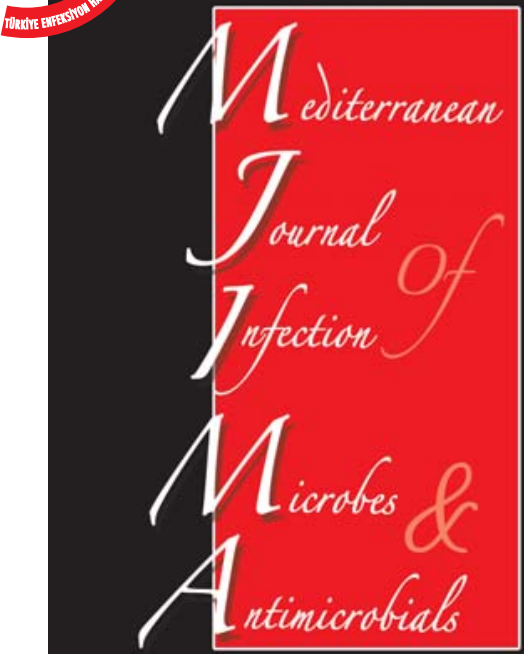

Aslıhan CANDEVIR ULU¹, Behice KURTARAN ${ }^{1}$, Ayşe Seza INAL ${ }^{1}$, Süheyla KÖMÜR ${ }^{1}$, Deniz TEKIN ${ }^{1}$, Hasan Salih Zeki AKSU , Yeşim TAŞOVA ${ }^{1}$

${ }^{1}$ Çukurova Üniversitesi Tıp Fakültesi, Enfeksiyon Hastalıkları ve Klinik Mikrobiyoloji Anabilim Dalı, Adana, Türkiye

${ }^{1}$ Department of Infectious Diseases and Clinic Microbiology, Faculty of Medicine, Cukurova University, Adana, Turkey

\section{ÖZET}

Giriş: Daptomisin 2009 yılının ikinci yarısından itibaren ülkemizde yumuşak doku enfeksiyonları ve endokarditte kullanılmaya başlanan gram pozitif etkili bir antibakteriyel ajandır. Bu çalışmada amacımız hastanemizde daptomisinin klinik çalışmalar haricinde nasıl kullanıldığını ve kullanan hastaların özellikleri ile tedaviye cevaplarını tespit etmekti.

Materyal ve Metod: Çalışmamızda 2009-2013 yılları arasında daptomisin kullanan hastalar retrospektif olarak değerlendirilmiştir. Hastaların demografik verileri, takip edildikleri klinikler, altta yatan hastalıklar, enfeksiyon bilgileri, üreyen mikroorganizmalar, tedavi ve klinik yanıt, yan etkiler kayıt edilmiş ve SPSS v20.0 programında analiz edilmiştir.

Bulgular: Çalışmaya verilerinin tamamına erişilen 139 hasta alındı (yaş ortalaması $52.9 \pm 16.4$, hastaların \%48.2'si erkek, \%58.1'i kadın). Hastaların 52'si (\%37.4) cilt ve yumuşak doku enfeksiyonu, 53'ü (\%38.1) osteomiyelit, 16'sı (\%11.5) protez eklem enfeksiyonu, yedisi primer kan dolaşımı enfeksiyonu (üç port enfeksiyonu, üç kateter ilişkili bakteremi ve bir laboratuvar kanıtlı bakteremi), dördü endokardit, üçü septik artrit, dördü de diğer enfeksiyonlar nedeniyle tedavi almıştır. Hastaların 107'sinde (\%77) tedavi ampirik olarak başlanmıştır. Toplamda \%68.6'sı gram-pozitif ve \%30'u gram-negatif olmak üzere 86 mikroorganizma üremesi olmuştur. Hastaların sadece 10'u (\%7.2) daha önce glikopeptit kullanmıştır. Tedavi sonu klinik yanıt \%85.6 olarak saptanmıştır. Gram-pozitif bakteri üremesi olan hastalarda tedavi sonu klinik başarı \%87,7 (50/57) olarak hesaplanmıştır, 12 hastada (\%8.6) yan etki gelişmiştir. Görülen yan etkilerin yedisi muhtemel eozinofilik pnömoni iken, iki hastada CK artışı bir hastada palpablpurpura, bir hastada cilt döküntüsü ve bir hastada renal fonksiyon bozukluğu saptanmıştır.

Sonuç: Daptomisinin, sıklıkla daha önceden tedavi almış, yumuşak doku enfeksiyonu ve osteomiyelit gibi komplike enfeksiyonlarda yüksek klinik başarı nedeniyle güvenle kullanılabilecek antibiyotik seçenekleri arasında olduğu görülmektedir. Gelecekte özellikle kemik eklem enfeksiyonlarında yapılacak randomize kontrollü çalışmalara ihtiyaç vardır.

Anahtar kelimeler: Daptomisin, klinik başarı, osteomiyelit, yumuşak doku enfeksiyonu, bakteremi

Geliş Tarihi: 21.11.2014 • Kabul Ediliş Tarihi: 23.12.2014 • Yayınlanma Tarihi: 31.12.2014 


\section{ABSTRACT}

Introduction: Daptomycin is an agent effective on gram-positive pathogens, which has been used since 2009 for skin and soft tissue infections and endocarditis. In this study, our aim was to see how daptomycin was used in our hospital besides clinical studies, and determine the characteristics of the patients and responses to treatment.

Materials and Methods: The patients who were started on daptomycin between 2009 and 2013 were retrospectively evaluated. Demographic characteristics, the clinics of the patients, underlying diseases, infection data, isolated microorganism, treatment and clinical response, and adverse events were recorded. SPSS v20.0 was used for analysis.

Results: The mean age of 139 patients were $52.9 \pm 16.4$, and $48.2 \%$ of the patients was male, $51.8 \%$ was female. Of the patients, $52(37.4 \%)$ were treated for skin and soft tissue infection; whereas, 53 (38.1\%) had osteomyelitis, 16 (11.5\%) had prosthetic infections, seven had primary blood stream infections (three port infections, three catheter associated bacteremia and one laboratory confirmed bacteremia), four had endocarditis, three had septic arthritis, and four had other infections. Treatment was started empirically in $77 \%$ of the patients $(n=107)$. Eighty-six microorganisms were isolated, of which $68.6 \%$ was gram positive and $30 \%$ was gram negative. Only ten patients (7.2\%) had used glycopeptides before. End of treatment response was $85.6 \%$ $(119 / 139)$ for all patients and $87.7 \%(50 / 57)$ for patients whose specimens yielded gram-positive microorganism. Twelve patients had adverse events (8.6\%). The adverse events were seven possible eosinophilic pneumonia, two CK elevations, one palpable purpura, one rash, and one renal function impairment.

Conclusion: Daptomycin is an alternative choice for complicated patient groups with complicated skin and soft tissue infections and osteomyelitis, randomized controlled studies especially on bone and joint infections are needed in the future.

Key words: Daptomycin, clinicalsuccess, osteomyelitis, skin and softt issue infection, bacteremia, endocarditis

Received: 21.11.2014 • Accepted: 23.12.2014 • Published: 31.12.2014

\section{GiRiș}

Dirençli gram-pozitif enfeksiyonların tedavisinde sıklıkla glikopeptitler kullanılmaktadır. Ancak zayıf eradikasyon güçleri ve yan etkileri nedeniyle daha etkin antibiyotik araştırma çalışmaları devam etmektedir. Son yıllarda linezolid ve tigesiklin gibi yeni antibiyotikler kullanıma girmiştir ve o antibiyotiklerden biri de daptomisindir. Daptomisin Streptomycesroseosporus tarafından üretilen hızı bakterisidal etkinliğe sahip, yapısı 13 üyeli amino asid siklik lipopeptid olan, gram pozitif etkili bir antibakteriyel ajandır. Daptomisin 1980'li yıllarda bulunmuştur ve o yıllardaki klinik çalışmalar yüksek doz kullanımına bağlı kas toksisitesi nedeniyle durdurulmuştur. Klinik çalışmalar 1999 yılında tekrar başlamıştır. Daptomisin "komplike deri ve yumuşak doku enfeksiyonları"nda 2003 yılında, "sağ kalp endokarditini de içeren Staphylococcus aureus bakteremisinde" ise 2006 yılında onay almıştır ${ }^{[1-4]}$. Bu çalışmanın amacı hastanemizde daptomisinin klinik çalışmalar haricinde nasıl kullanıldığını ve kullanan hastaların özellikleri ile tedaviye cevaplarını tespit etmektir.

\section{MATERYAL ve METOD}

Çukurova Üniversitesi Tıp Fakültesi Hastanesi'nde 2009-2013 yılları arasında daptomisin kullanan hastalar retrospektif olarak değerlendirilmiştir. Eczane oto- masyon sisteminden daptomisin kullanan hasta bilgileri alındıktan sonra hastaların verileri (demografik veriler, takip edildikleri klinikler, altta yatan hastalıklar, enfeksiyon bilgileri, üreyen mikroorganizma, tedavi ve tedavi cevabı, yan etkiler vb.) otomatize sistem ve konsültasyon notlarından retrospektif olarak incelenmiş, standart hasta formlarına kayıt edilmiştir.

Inceleme sonunda 146 hasta dosyasına ve bilgilerine ulaşılırken 139 hasta çalışmaya alınmıştır. Enfeksiyon tanıları hastanın ilgili sistem bulguları eşliğinde ateş, lökositoz, akut faz reaktan yüksekliği ve görüntüleme yöntemleri kullanılarak konulmuştur. Erizipel, selülit gibi yüzeyel enfeksiyonları cilt ve yumuşak doku enfeksiyonu (CYDE) olarak kabul edilirken, daha derin enfeksiyonlar ve apse ile altta yatan diabetes mellitus, venözstaz, bası yarası, perianal selüliti olan hastalarda gelişen ve/veya cerrahi gerektiren CYDE'leri komplike olarak kabul edilmiştir. Osteomiyelit tanısı klinik bulgular, akut faz reaktanları ve pozitif radyolojik bulgulara dayanarak konulmuştur. Endokardit tanısında Duke kriterleri kullanıldı ${ }^{[5]}$. Primer kan dolaşımı enfeksiyonu tanısı, patojen olduğu bilinen bir mikroorganizmanın bir veya birden fazla kültürde üremesi ve başka yerdeki bir enfeksiyon ile ilişkili olmaması veya ateş, titreme, hipotansiyon varlığında cilt florası bakte- 
rilerin farklı zamanda alınan en az iki ayrı kan kültüründe üremesi ile konulmuştur. Santral venöz kateteri olan hastalar primer kan dolaşımı enfeksiyonu olarak kabul edilmiştir.

Klinik örneklerin klasik olarak önerilen standart besiyerlerine (bioMérieux) ekimleri yapılmış ve inkübasyon sürelerinin sonunda, standart mikrobiyolojik yöntemlerle karakteristik özellikleri belirlenen kolonilerin, otomatize VITEK 2 sistem (bioMérieux) kullanılarak identifikasyonları ve antibiyotik duyarlıık testleri yapılmıştır. Bakteri duyarlııı sonuçları "Clinicaland Laboratory Standards Institute (CLSI)" tarafından belirlenen kriterlere göre değerlendirilmiştir ${ }^{[6]}$.

Tedavi sonunda klinik başarı, tamamen iyileşme veya belirti ve bulgularda azalma, radyolojik düzelme ve/veya akut faz reaktanlarında düzelme olarak kabul edilmiştir. Tedaviyi herhangi bir şekilde bırakma, klinikte, akut faz reaktanlarında, ve/veya radyolojik bulgularda düzelme olmaması veya düzeldikten sonra tekrar kötüleşme olması tedavi başarısızığı olarak kabul edilmiştir. Tedaviye cevap kriterleri EU-CORE çalışmasında tarifli klinik başarı tanımı ile örtüşmektedir; bu çalışmada klinik başarı, kür veya klinik belirti ve bulgularda tam olmayan düzelme olması şeklinde tanımlanmıştır ${ }^{[7]}$. Çalışmada mikrobiyolojik başarı değerlendirilmemiştir.

Elde edilen veriler SPSS v20.0 programında analiz edilmiştir.

\section{BULGULAR}

Çalışmaya verilerinin tamamına erişilen 139 hasta alındı (yaş ortalaması $52.9 \pm 16.4$, hastaların \%48,2'si erkek). Hastaların 83 (\%59.7)'ü enfeksiyon hastalıkları kliniğinde takip edilirken, 28 (\%20.1); diğer dahili klinikler, $28(\% 20,1)$; cerrahi kliniklerde takip edilmiştir. Hastalara ait altta yatan özellikler Tablo 1'de özetlenmiştir.

Hastaların 52 (\%37.4)'si CYDE için tedavi almışken, 53'ü (\%38.1) osteomiyelit, 16 (\%11.5)'sı protez eklem enfeksiyonu, yedisi primer kan dolaşımı enfeksiyonu (üç port enfeksiyonu, üç kateter ilişkili bakteremi ve bir laboratuvar kanıtlı bakteremi), dördü endokardit, üçü septik artrit, dördü de diğer enfeksiyonlar nedeniyle tedavi almıştır.

\begin{tabular}{lcc} 
Tablo 1. Hastaların altta yatan hastalıkları & \\
\hline & $\mathbf{n}$ & $\%$ \\
\hline Nötropeni & 7 & 5 \\
Kronik böbrek hastalığı & & \\
Cr klirensi <30 & 15 & 10.8 \\
Diyaliz & 13 & 9.4 \\
DM & 41 & 29.5 \\
Malignite & 14 & 10.1 \\
Ortopedik cerrahi & 53 & 38.1
\end{tabular}

Hastaların 107 (\%77)'sinde tedavi ampirik olarak başlanmıştır. Hastaların 74 (\%53.2)'ünde kültürde üreme yokken, 50 hastada bir mikroorganizma, 18 hastada ise birden çok olmak üzere toplam 86mikroorganizma üremesi olmuştur. Üreyen mikroorganizmaların \%68.6'sı, gram-pozitif, \%30'u gram-negatif olarak tespit edilmiştir (Tablo 2).

\section{Tablo 2. Etken mikroorganizmaların dağılımı}

\begin{tabular}{|c|c|c|}
\hline & $\mathbf{n}$ & $\%$ \\
\hline \multicolumn{3}{|l|}{ Staphylococcus aureus } \\
\hline Metisilin hassas & 8 & 9.3 \\
\hline Metisilin dirençli & 8 & 9.3 \\
\hline \multicolumn{3}{|l|}{ Koagülaz negatif stafilokok } \\
\hline Metisilin hassas & 8 & 9.3 \\
\hline Metisilin dirençli & 19 & 22.1 \\
\hline Streptococcus spp. & 7 & 8.1 \\
\hline Enterococcus feacalis & 5 & 5.8 \\
\hline Enterococcus faecium & 3 & 3.5 \\
\hline \multicolumn{3}{|l|}{ Klebsiella pneumoniae } \\
\hline GSBL (-) & 1 & 1.2 \\
\hline GSBL (+) & 2 & 2.3 \\
\hline \multicolumn{3}{|l|}{ Escherichia coli } \\
\hline GSBL (-) & 1 & 1.2 \\
\hline GSBL (+) & 8 & 9.3 \\
\hline Acinetobacter baumannii & 4 & 4.7 \\
\hline Proteus mirabilis & 2 & 2.3 \\
\hline Pseudomonas aeruginosa & 2 & 2.3 \\
\hline Diğer & 8 & 9.3 \\
\hline Toplam & 86 & 100.0 \\
\hline
\end{tabular}


Tablo 3. Tanılara göre daptomisin kullanım süreleri

\begin{tabular}{|c|c|c|c|c|c|c|}
\hline Tanı & $\mathbf{N}$ & Ortalama & SS & Median & Alt değer & Üst değer \\
\hline $\mathrm{CYDE}^{*}$ & 52 & 18.04 & 13.14 & 14.00 & 2 & 66 \\
\hline Osteomyelit & 53 & 29.79 & 20.39 & 25.00 & 4 & 120 \\
\hline Primer $\mathrm{KDE}^{* *}$ & 7 & 15.57 & 7.76 & 14.00 & 5 & 30 \\
\hline Endokardit & 4 & 20.00 & 11.58 & 22.00 & 6 & 30 \\
\hline Protez enfeksiyonu & 16 & 29.94 & 13.31 & 26.00 & 12 & 60 \\
\hline Septik artrit & 3 & 12.33 & 8.50 & 9.00 & 6 & 22 \\
\hline Diğer & 4 & 12.75 & 2.22 & 13.00 & 10 & 15 \\
\hline
\end{tabular}

* CDYE: Cilt yumuşak doku enfeksiyonu, KDE: Kan dolaşımı enfeksiyonu, SS: Standart sapma.

Hastaların 85 (\%61.2)'inde daptomisin öncesi başka bir antibiyotik kullanım öyküsü mevcuttur. Hastaların sadece 10 (\%7.2)'u daha önce glikopeptit kullanmış, linezolid ve tigesiklin kullanımı ise daha az sıklıkta saptanmıştı; sırasıyla \%2.2 $(n=3), \% 6.5(n=9)$. Hastaneye yattığında ilk sıra olarak daptomisin tedavisi 73 (\%52.5)'ünde verilmiş ve sadece 22 (\%15.8)'sinde tek başına daptomisin kullanmıştır. Ortalama daptomisin kullanım süresi $23.6 \pm 17$ gün olarak tespit edilmiştir; yumuşak doku enfeksiyonlarında $18 \pm 13.1$ gün, osteomiyelitte $29.8 \pm 20.4$ gün, protez enfeksiyonlarında $29.9 \pm 13.3$ gün (Tablo 3 ).

Hastaların \%82.7'sinde $(n=115)$ eş zamanlı antibiyotik kullanımı mevcuttur. Bu hastalarda en sık kullanılan antibiyotik karbapenem grubu $(n=44, \% 38.2)$ iken bunu siprofloksasin $(n=31, \% 27)$ ve piperasilin tazobaktam ( $n=26, \% 22.6$ ) takip etmiştir.

Daptomisinin en sık sonlandırılma nedeni tedavinin tamamlanması (\%77, $\mathrm{n}=107$ ) iken 12 hastada yan etkiler (\%8.6), dokuz hastada deeskalasyon uygulanması (\%6.5) ve iki hastada tedavi başarısızlığı (\%1.4) olmuştur. Hastalardan 9 (\%6.5)'u kendi isteğiyle hastaneden taburcu olmuştur. Görülen yan etkilerin yedisi muhtemel eosinofilik pnömoni iken iki hastada CK artışı, bir hastada palpablpurpura, bir hastada cilt döküntüsü ve bir hastada renal fonksiyon bozukluğudur. Muhtemel eosinofilik pnömoni tanısı alan hastalardan biri yoğun bakım takibinde kaybedilmiştir (mortalite oranı \%0.7).
Tedavi sonu klinik başarı \%85.6 (119/139) olarak hesaplanırken, gram-pozitif üremesi olan 57 hastada tedavi sonu klinik başarı \%87.7 $(n=50)$ olarak hesapIanmıştır. Tanılara göre tedavisi sonu klinik başarı Tablo 4'te gösterilmiştir.

\section{TARTIȘMA}

Gram-pozitif enfeksiyonlar deri yumuşak doku ve kemik eklem sistemi enfeksiyonlarında en sık görülen etkenlerdir. Vankomisinin dirençli gram-pozitif enfeksiyonların tedavisinde altın standart olarak süregelmesine rağmen glikopeptit toleransının ve direncinin tedavi başarısızlığına yol açması, alternatif ajanların kullanım zorunluluğunu getirmektedir. Daptomisin son yıllarda özellikle kemik eklem enfeksiyonlarında etkili bir tedavi alternatifi olarak öne çıkmaktadır ${ }^{[8-10]}$. Bizim çalışmamızda da hastaların yarısından fazlasında kemik eklem enfeksiyonu için daptomisin kullanmıştır.

Daptomisinin kullanıldığı üç olgu serisinde hastaların \%43'ünde osteomiyelit tespit edilmiş ve diğer enfeksiyonlar arasında total kalça protez enfeksiyonu, laminektomi bölge enfeksiyonu, diz apsesi ve septik artritle ilişkili bakteremi bulunmaktadır ${ }^{[11-14]}$. Bu çalışmalarda hastaların \% 74'ünde MRSA etken olarak tespit edilmiş ve hastaların \%11'inde birden fazla patojen tespit edilmiştir. Daptomisin 4-6 mg/kg dozda ortalama 37.4 gün verilmiş ve vakaların \%81'inde kür elde edilmiştir. Osteomiyelit vakalarında kür $\% 100$ iken protez enfeksiyonlarında \%60 olarak bulunmuştur. Bizim çalışmamIzda MRSA düşük oranda tespit edilse de izole edilen 


\begin{tabular}{|c|c|c|c|c|c|c|c|c|c|c|c|}
\hline \multirow[t]{2}{*}{ Tanı } & \multicolumn{2}{|c|}{ S. aureus } & \multicolumn{2}{|c|}{ KNS } & \multicolumn{2}{|c|}{ Enterococcus spp. } & \multirow[b]{2}{*}{ Streptococcuss spp. } & \multirow[b]{2}{*}{ Diğer } & \multirow[b]{2}{*}{ Toplam } & \multicolumn{2}{|c|}{ Klinik başarı } \\
\hline & MS & MR & MS & MR & E. feacalis & E. faecium & & & & $\mathbf{N}$ & $\%$ \\
\hline \multirow{2}{*}{ YDE } & 2 & 1 & 5 & 7 & 3 & 1 & 2 & 12 & 33 & 47 & 90.4 \\
\hline & $\% 6.1$ & $\% 3.0$ & $\% 15.2$ & $\% 21.2$ & $\% 9.1$ & $\% 3.0$ & $\% 6.1$ & $\% 36.4$ & $\% 100.0$ & & \\
\hline \multirow{2}{*}{ Osteomyelit } & 2 & 6 & 2 & 2 & 1 & 0 & 1 & 7 & 21 & 44 & 83 \\
\hline & $\% 9.5$ & $\% 28.6$ & $\% 9.5$ & $\% 9.5$ & $\% 4.8$ & $\% 0.0$ & $\% 4.8$ & $\% 33.3$ & $\% 100.0$ & & \\
\hline \multirow{2}{*}{ Primer KDE } & 3 & 0 & 0 & 0 & 0 & 0 & 0 & 3 & 6 & 7 & 100 \\
\hline & $\% 50.0$ & $\% 0.0$ & $\% 0.0$ & $\% 0.0$ & $\% 0.0$ & $\% 0.0$ & $\% 0.0$ & $\% 50$ & $\% 100.0$ & & \\
\hline \multirow{2}{*}{ Endokardit } & 0 & 0 & 0 & 2 & 0 & 1 & 1 & 1 & 5 & 2 & 50 \\
\hline & $\% 0.0$ & $\% 0.0$ & $\% 0.0$ & $\% 60.0$ & $\% 0.0$ & $\% 20.0$ & $\% 0.0$ & $\% 20$ & $\% 100.0$ & & \\
\hline \multirow{2}{*}{$\begin{array}{l}\text { Protez } \\
\text { enfeksiyon }\end{array}$} & 1 & 1 & 0 & 8 & 1 & 0 & 2 & 2 & 15 & 15 & 93,8 \\
\hline & $\% 6.7$ & $\% 6.7$ & $\% 0.0$ & $\% 53.3$ & $\% 6.7$ & $\% 0.0$ & \%13.3 & \%13.3 & \%100.0 & & \\
\hline \multirow{2}{*}{ Septik artrit } & 0 & 0 & 1 & 0 & 0 & 0 & 1 & 0 & 2 & 2 & 66,7 \\
\hline & $\% 0.0$ & $\% 0.0$ & $\% 50.0$ & $\% 0.0$ & $\% 0.0$ & $\% 0.0$ & $\% 50.0$ & $\% 0$ & \%100.0 & & \\
\hline \multirow{2}{*}{ Diğer } & 0 & 0 & 0 & 0 & 0 & 1 & 0 & 3 & 4 & 2 & 50 \\
\hline & $\% 0.0$ & $\% 0.0$ & $\% 0.0$ & $\% 0.0$ & $\% 0.0$ & $\% 25$ & $\% 0.0$ & $\% 75$ & \%100.0 & & \\
\hline \multirow{2}{*}{ Toplam } & 8 & 8 & 8 & 19 & 5 & 3 & 7 & 28 & 86 & 119 & 85.6 \\
\hline & $\% 9.3$ & $\% 9.3$ & $\% 9.3$ & $\% 22.1$ & $\% 5.8$ & $\% 3.5$ & $\% 8.1$ & \%32.6 & \%100.0 & & \\
\hline Klinik başarı & $7 / 8$ & $8 / 8$ & $7 / 8$ & $17 / 19$ & $4 / 5$ & $2 / 3$ & $6 / 7$ & $17 / 28$ & & & \\
\hline
\end{tabular}

MS: Metisilin hassas, MR: Metisilin dirençli, YDE: Yumuşak doku enfeksiyon, KDE: Kan dolaşımı enfeksiyonu.

mikroorganizmaların yaklaşık 2/3'ü gram-pozitif olarak saptanmıştır.

Boucher ve arkadaşlarının S.aureus'a bağlı kemik ve eklem enfeksiyonlarında standart tedaviyle daptomisinin karşılaştırdığı çalışmada, tedavi sonu tedavi başarısı \%76.2 olarak bulunmuştur ve tedavi sonu 6 . haftada da \%66.7 olarak tespit edilmiştir ${ }^{[15]}$. ABD'de 6 merkezde yapılan retrospektif bir incelemede en sık osteomiyelit etkeni MRSA olarak bulunmuş (\%64) ve hastaların \%52'si tedavi başında daptomisin ile beraber vankomisin tedavisi almış. Bu çalışmada tedavi sonu kür \%55, iyileşme \%34 ve tedavi başarısızlığı $\% 10$ olarak tespit edilmiştir $(n=29)^{[16]}$. Bu çalışmada ortanca tedavi süresi 42 (18-63) gün olarak hesaplanmıştır.

6 (4-6.2) $\mathrm{mg} / \mathrm{kg}$ daptomisin ile ortanca 38 (6-59) gün tedavi edilen 25 ayak ve bilek osteomiyelitinde yine ana etken MRSA olarak tespit edilmiş ve tedavi sonunda 16 hasta tamamen düzelirken 9 hastanın durumu daha iyiye gitmiştir. 3 hastada tedavi başarısızığı olmuştur ${ }^{[17]}$. Hastaların 23 'ünde daptomisin ikinci sıra tedavi olarak kullanılmış ve \%52 hastada gram-negatif bakterileri de kapsamak amaçlı ek antibiyotik kullanılmıştır. Yazarlar sonuç olarak daha önceden tedavi edilmiş ayak ve bilek osteomiyelitinde daptomisinin iyi bir tedavi seçeneği olduğu görüşüne varmışlardır.

Çok merkezli daptomisin ile tedavi edilmiş hastaları inceleyen gözlemsel çalışmada (EU-CORE) hasta özellikleri ve tedavi cevapları araştııımış, genel tedavi başarısı \%78.4 olarak saptanırken daha önceden tedavi almamış hastalarda başarı \%81.5, kurtarma tedavisi olarak kullanıldığında ise $\% 77.6$ olarak hesaplanmıştı ${ }^{[18]}$. Osteomiyelit hastalarında \%63 kür elde edilmiş ve hastaların \%19'unun semptom ve bulgularının iyileştiği gözlenmiştir ${ }^{[19]}$. Yaklaşık hastaların yarısında (\%48) eşlik eden antibiyotik kullanımı mevcuttur ve vakaların $\% 45$ 'inde etken patojen MRSA olarak bulunmuştur. Daptomisinin tek başına kullanıldığı hastalarda \%94 klinik başarı ile klinik pratikte gram-pozitif mikro organizmalara bağlı osteomiyelitte güvenle kullanabileceği sonucu çıkarılmıştır. 
Tedavi başarısı çeşitli merkezlerde \%66.5 ile \%100 arasında bildirilirken bu durum tedavi başarısı tanımlarındaki farklılıklara bağlanmıştır. Bizim hastalarımızın da Holtom ve arkadaşları ile benzer şekilde çoğunda daptomisin öncesi başka bir antibiyotik kullanım öyküsü mevcuttur. Buna ve çalışmamızdaki ortanca tedavi sürelerinin literatüre göre daha kısa olmasına rağmen, tedavi başarısı oldukça yüksek şekilde \%88 olarak tespit edilmiştir. Bunun yanında çoğunlukla tedavi ampirik başlandığı için, yine literatür ile benzer şekilde hastaların çoğunda eşlik eden antibiyotik kullanımı mevcuttur.

Daptomisinin komplike CYDE'lerin tedavisindeki etkinliği uluslararası, çok merkezli, randomize kontrollü faz 3 klinik çalışmayla araştırılmıştır. Yara enfeksiyonu, abse, diyabetik ayak enfeksiyonu ve diğer ülserler dahil 902 hasta komplike yumuşak doku enfeksiyonu olarak alınmıştır. Standart tedavide vankomisin kullanılmış, daptomisin kolunda klinik başarı oranı \%83.4 iken, standart tedavi kolunda başarı oranı \%84.2 saptanmıştır. Daptomisin ile tedavi olan hastaların yarısından fazlasında tedavi süresi kısa olarak tespit edilirken (\%63), standart tedavi uygulanan hastaların sadece \%33'ünün tedavi süresi kısa olarak belirlenmiştir. Daptomisin komplike CYDE'de daha kısa sürede etkin olarak bulunmuştur ${ }^{[20]}$. Bizim çalışmamızda da benzer şekilde yumuşak doku enfeksiyonlarında ortanca 14 (2-66) günde \%90.4 oranında başarılı bulunmuştur.

Wang ve arkadaşlarının yaptığı cilt ve yumuşak doku enfeksiyonlarında daptomisinin etkinlik ve güvenilirliği meta-analizinde daptomisin diğer ilk sıra ajanlarla benzer ve hatta biraz daha etkili olarak bulunmuş (Klinik başarı için OR= 1.05, \%95 GA: 0.84-1.31, $p=$ 0.65 ) ve bunun yanında diğer ajanlarla benzer yan etki profiline sahip olduğu gösterilmiştir (OR=1.06, \%95 GA $0.71-1.59, p=0.76)$. Daptomisin kullanan grupta anlamIı bir şekilde daha fazla hastada kreatinin fosfokinaz yüksekliği olmuş ancak tedaviyle normale dönmüştür ${ }^{[21]}$. Aikawa ve arkadaşları daptomisine bağlı yan etkileri \%21.6 oranında bulurken, CK yüksekliği sadece bir hastada olmuş $(n=88)$. Konychev ve arkadaşları ise yan etki oranın \%13.8 olarak tespit etmişlerdir ve yine 1/81 hastada CK yüksekliği gözlenmiştir ${ }^{[22,23]}$. Bizim çalışmamızda da literatür ile benzer oranlarda, 12 hastada yan etki gelişmiş (\%8.6), Görülen yan etkilerin yedisi muhtemel eosinofilik pnömoni iken iki CK artışı bir de palpablpurpura ve bir renal fonksiyon bozukluğu görülmüştür.

Daptomisinin ruhsat aldıktan sonraki ilk yıllarda kullanımını inceleyen ve sekiz ülkeden verilerin kullanıldığı EU-CORE çalışmasında 1127 hasta çalışmaya alınmış, bunların 373'ü primer komplike CYDE iken 244'ü bakteremi tanısı almıştır. Tedavi başarısı komplike CYDE'de \%81 bulunurken, bakteremide \%77 ve S.aureus enfeksiyonlarında ise $\% 82$ olarak bulunmuştur. Bu oranlar bizim çalışmamızdaki yüksek başarı oranları ile benzerdir ${ }^{[24]}$.

Endokarditteki etkinliğine yönelik yapılan bir hayvan çalışmasında, yüksek S.aureus bakteri yükü olan endokarditli vakalarda kloksasilin ve vankomisine göre daha yüksek bakterisidal aktiviteye sahip olduğu ve vejetasyonda serum konsantrasyonunun \%50'sine ulaşarak vankomisinden daha iyi geçiş gösterdiği bulunmuştur ${ }^{[25]}$. Daptomisinin bakteriyemi ve sağ taraf endokarditli hastalarda kullanımı ile ilgili faz 3 çalışması mevcuttur. Fowler ve arkadaşları S.aureus bakteriyemisi ve/veya endokarditi olan toplam 246 hastada daptomisinin etkinliğini düşük doz aminoglikozidle birlikte antistafilokokkal penisilin veya vankomisin ile karşılaştırmışlardır. MRSA izolatlarına karşı klinik başarı vankomisinle \%31.8 daptomisinle \%44.4, MSSA izolatlarında ise antistafilokokal penisilinler/vankomisinle \%48.6 daptomisinle ise $\% 44.6$ oranında saptanmıştır. Bu çalışmanın alt grup analizlerinde ise komplike bakteriyemi, sağ yan endokarditi ve MRSA bakteriyemilerinde etkinlikleri benzer olarak bulunmuştur ${ }^{[26]}$. Kateter ilişkili bakteriyemide daptomisinin etkinlik ve güvenilirliğinin irdelendiği bir başka çalışmada ise, daptomisin ile erken klinik ve mikrobiyolojik cevap alındığı gösterilmiştir ${ }^{[27]}$. Bizim çalışmamızda ise az sayıda olan bu hasta grubunda başarılı sonuçlar elde edilmiştir. Yedi bakteremi olgusunda \%100 başarı elde edilirken dört endokardit olgusunun ikisinde tedavi başarısı sağlanmıştır. Çalışmamızda kan dolaşım sistemi enfeksiyonu nedeniyle tedavi alan hasta sayısının azlığı dikkati çekmektedir. Bu hastanemizde kateter ilişkili kan dolaşım sistemi enfeksiyonu insidansının düşük olmasına ve etken olarak da S.aureus'un son 10 yıldır giderek azalan sıklıkta \%10'un altında görülmesine bağlanmıştır (yayınlanmamış hastane enfeksiyon kont- 
rol komitesi verileri).

Sonuç olarak daptomisin, sıklıkla daha önceden tedavi almış, yumuşak doku enfeksiyonu ve osteomiyelit gibi komplike hasta gruplarında yüksek klinik başarı ile güvenle kullanılabilecek antibiyotik seçenekleri arasındadır. Gelecekte kemik eklem enfeksiyonlarında yapılacak randomize kontrollü çalışmalara intiyaç vardır.

\section{KAYNAKLAR}

1. Tedesco KL, Rybak MJ. Daptomycin. Pharmacotherapy 2004;24:41-57.

2. Snydman DR, Jacobus NV, McDermott LA, Lonks JR, Boyce JM. Comparative in vitro activities of daptomycin and vancomycin against resistant gram-positive pathogens. Antimicrob Agents Chemother 2000;44:3447-50.

3. Carpenter CF, Chambers HF. Daptomycin: Another novel agent for treating infections due to drug-resistant grampositive pathogens, Clin Infect Dis 2004;38:994-1000.

4. Tabak F. 2010'da daptomisin. Ankem Derg 2010; 24(Suppl 2):S110-S3.

5. Durack DT, Lukes AS, Bright DK. New criteria for diagnosis of infective endocarditis: Utilization of specifice chocardiographic findings: Duke Endocarditis Service. Am J Med. 1994;96:200-9.

6. Clinical and Laboratory Standards Institute 2012. Performance standards for antimicrobial susceptibility testing. Twenty-second informational supplement. M100-S22. CLSI; Wayne, PA; 2012.

7. Gonzalez-Ruiz A, Beiras-Fernandez A, Lehmkuhl $H$, Seaton RA, Loeffler J, Chaves RL. Clinical experience with daptomycin in Europe: the first 2.5 years. J Antimicrob Chemother. 2011;66:912-9.

8. Hiramatsu K. Vancomycin-resistant Staphylococcus aureus: a new model of antibiotic resistance. Lancet Infect Dis 2001;1:147-55.

9. Ward PB, Johnson PD, Grabsch EA, Mayall BC, Grayson $M L$. Treatment failure due to methicillin-resistant Staphylococcus aureus (MRSA) with reduced susceptibility to vancomycin. Med J Aust 2001;175:480-3

10. Cunha BA. Methicillin-resistant Staphylococcus aureus: clinical manifestations and antimicrobial therapy. Clin Microbiol Infect 2005;11(Suppl 4):S33-S42.

11. Finney MS, Crank CW, Segreti J. Use of daptomycin to treat drug-resistant gram-positive bone and jointin fections. Curr Med Res Opin 2005;21:1923-6.
12. Antony SJ, Angelos E, Stratton CW. Clinical experience with daptomycin in patients with orthopedic related infections. Infect Dis Clin Pract 2006;14:144-9.

13. Rao N, Regalla DM. Uncertain efficacy of daptomycin for prosthetic joint infections: A prospective case series. Clin Orthop Relat Res 2006;451:34-7.

14. Falagas ME, Siempos II, Papagelopoulos PJ, Vardakas $K Z$. Linezolid for the treatment of adults with bone and joint infections. Int J Antimicrob Agents 2007;29:233-9

15. Balter L, Donovan B, North D, Lamp K, Friedrich L. Retrospective evaluation of daptomycin efficacy and safety in patients with osteomyelitis. Presented at $44^{\text {th }}$ annualmeeting of the Infectious Disease Society of America Meeting, 2006 Oct 12-15; Toronto, ON, Canada; Abstract 208, p.82-3.

16. Rice DA, Mendez-Vigo L. Daptomycin in bone and joint infections: a review of the literature. Arch Orthop Trauma Surg 2009;129:1495-504.

17. Holtom PD, Zalavras CG, Lamp KC, Park N, Friedrich LV. Clinical experience with daptomycin treatment of foot or ankle osteomyelitis: A preliminary study. Clin Orthop Relat Res 2007;461:35-39.

18. Cercenado E, Pachón J. The EUCORE registry: objectives and general results. Enferm Infecc Microbiol Clin 2012;30 (Suppl 1):S3-S9.

19. Lamp KC, Friedrich LV, Mendez-Vigo L, Russo R. Clinical experience with daptomycin for the treatment of patients with osteomyelitis. Am J Med 2007;120: (suppl 1):S13-S20.

20. Arbeit RD, Maki D, Tally FP, Campanaro E, Eisenstein BI; Daptomycin 98-01 and 99-01 Investigators. The safety and efficacy of daptomycin for the treatment of complicated skin and skin-structure infections. Clin Infect Dis 2004;38:1673-81.

21. Wang SZ, Hu JT, Zhang C, Zhou W, Chen XF, Jiang $L Y$, et al. The safety and efficacy of daptomycin versus other antibiotics for skin and soft-tissue infections: A metaanalysis of randomised controlled trials. BMJ Open 2014;4:e004744.

22. Aikawa N, Kusachi S, Mikamo H, Takesye Y, Watanabe S, Tanaka $Y$, et al. Efficacy and safety of intravenous daptomycin in Japanese patients with skin and soft tissue infections. J Infect Chemother 2013;19:447-55.

23. Konychev A, Heep M, Moritz RK, Kreuter A, Shulutko A, Fierlbeck $G$, et al. Safety and efficacy of daptomycin as first-line treatment for complicated skin and soft tissue infections in elderly patients: An open-label, multicentre, randomized phase IIIb trial. Drugs Aging 2013;30:829-3. 
24. Gonzalez-Ruiz A, Beiras-Fernandez A, Lehmkuhl H, Dohmen PM, Loeffler J, Chaves RL. Effectiveness and safety of daptomycin in complicated skin and soft-tissue infections and bacteraemia in clinical practice: results of a large non-interventional study. Int $J$ Antimicrob Agents 2013;41:372-8.

25. Cantoni L, Glauser MP, Bille J. Comparative efficacy of daptomycin vancomycin and cloxacillin for the treatment of Staphylococcus aureus endocarditis in ratsand role of test conditions in this determination. Antimicrob Agents Chemother 1990;34:2348-53.

26. Fowler VG Jr, Boucher HW, Corey R, Abrutyn E, Karchmer AW, Rupp ME, et al. Daptomycin versus standard therapy for bacteremia and endocarditis cause by Staphylococcus aureus. N Engl Med J med 2006;355:653-65.

27. Chaftari AM, Hachem R, Mulanovich V, Chemaly RF, Adachi J, Jacobson $K$, et al. Efficacy and safety of daptomycin in the treatment of Gram-positive catheter-related bloodstream infections in cancer patients. Int $J$ Antimicrob Agents 2010;36:182-6.

\section{Yazışma Adresi /Address for Correspondence}

Yrd. Doç. Dr. Aslıhan CANDEviR ULU Çukurova Üniversitesi Tıp Fakültesi,

Enfeksiyon Hastalıkları ve Klinik Mikrobiyoloji Anabilim Dalı Adana/TÜRKIYE

E-posta: acandevir@gmail.com 